\title{
Clinical and Circulatory Effects of Neuroleptanalgesia with Dehydrobenzperidol and Phenoperidine
}

\author{
H. R. MACDONALD, D. P. BRAID, B. R. STEAD, I. C. CRAWFORD, \\ AND S. H. TAYLOR \\ From the Departments of Medicine, Ancesthetics, and Cardiology, at the Royal Infirmary, Edinburgh
}

The majority of cardiovascular laboratories concerned with diagnostic investigations routinely employ a variety of analgesic and sedative drugs during intravascular procedures. There is little doubt that many of these drugs have significant

\section{Pharmacology}

Dehydrobenzperidol. This drug, marketed under the trade name of droperidol, is one of the butyrophenone series of neuroleptic drugs with the configuration shown below.

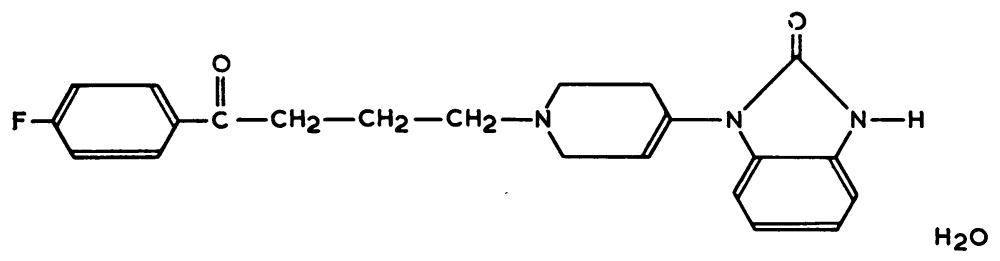

hæmodynamic effects. At present the most commonly used sedatives are probably the barbiturate or opiate derivatives, but both groups of drugs have been shown to produce notable circulatory changes. The search, therefore, continues for drugs of equal sedative power but with less direct effects on the circulation.

Dehydrobenzperidol and phenoperidine in combination have achieved some popularity for their analgesic and sedative effects during neurosurgical stereotaxic operations (Brown, 1964). A distinctive feature of these drugs has been the complete freedom of the patient from any distress during this exacting procedure, while full powers of co-operation are retained. Moreover, this drug combination caused no appreciable change in heart rate or blood pressure. Such drug-induced neuroleptanalgesia might therefore be superior to the methods of sedation generally used for cardiovascular procedures. The present report concerns a trial of these drugs alone and in combination in patients with rheumatic heart disease undergoing diagnostic circulatory investigation; it also attempts more detailed analysis of their hæmodynamic effects.

Received October 21, 1965.
In the conscious experimental animal, dehydrobenzperidol (DHBP) produces a marked cataleptic state with powerful inhibition of conditioned reflexes. High doses of the drug are associated with a fall in the systemic vascular resistance and blood pressure, and these circulatory effects are significantly potentiated by anæsthesia or barbiturates. However, in the doses usually employed these circulatory changes are minimal. The drug also appears to block the circulatory effects of exogenous catecholamines, both in the rat and the cat. In the anæsthetized dog, the drug seems to produce a conspicuous hypersensitivity to carbon dioxide with an increase in the minute ventilation. These effects of the drug in the experimental animal have been presented in more detail by Janssen et al. (1963).

In conscious patients undergoing neurosurgical stereotaxic operations, DHBP has been used in doses up to $10 \mathrm{mg}$, given by intramuscular or intravenous injection. One of the most remarkable effects of the drug has been to induce a state of indifference to immediate surroundings and current events and a predisposition to sleep. In a small minority of subjects, certain bizarre sensations have been described, such as loss of body image, a feeling 
of weightlessness and restlessness, though, to the observer, even patients in the latter group appear to be completely sedated and relaxed while under its influence. The effects of the drug on the circulatory and respiratory systems in these patients have been minimal. Apart from an initial slight hypotensive effect, no circulatory changes were observed, and no respiratory effects were evident (Brown, Horton, and MacRae, 1963).

Dehydrobenzperidol may be given by intramuscular or intravenous injection. The duration of its neurological effects is from 24-36 hours following a single injection of $10 \mathrm{mg}$., but its distribution, metabolism, and mode of excretion are unknown. Large doses of the drug may produce transient Parkinsonian-like extrapyramidal disturbances which have been shown to be readily controlled by small doses of chlorpromazine (Brown, 1963).

Phenoperidine. This drug is a derivative of pethidine, the N-methyl group being replaced by a phenyl-propinyl chain. It has the following chemical configuration:

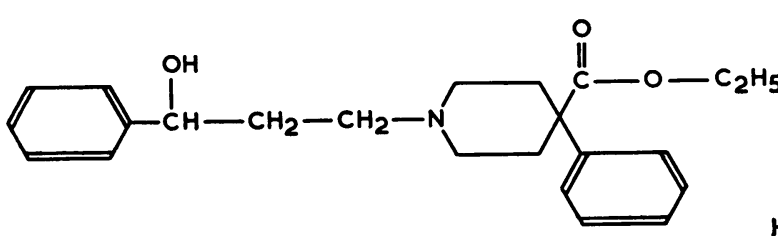

The effect of the drug in animals appears to be very similar to that of morphine. The first effect of the drug is to produce a reduced state of reactivity to noxious stimuli; this is followed by increasing depression of brain-stem function as the dose is increased up to a state of respiratory failure. These effects are rapidly and apparently completely reversed by nalorphine. The effects of the drug on the circulation in animals are not known.

In man, phenoperidine has powerful analgesic and sedative properties. Although respiratory depression occurs, particularly if a dose of $2 \mathrm{mg}$. is exceeded, few effects on the circulation have been described (Rollason and Sutherland, 1963). A troublesome side-effect, restricting the use of the drug alone, is its powerful emetic activity. It may be given orally, intramuscularly, or intravenously. Approximately 50 per cent of the injected dose is excreted unchanged in the urine, the remainder being successively broken down to pethidine and pethidinic acid, 75 per cent of which is eliminated by the kidneys.

\section{Clinical Trial}

DHBP, alone or in combination with pheno-
$\mathrm{HCl}$ muscular injection in a dose of $10 \mathrm{mg}$. two hours before the procedure. The other 8

peridine, was administered to 65 patients undergoing diagnostic cardiac investigation to assess their suitability for surgical treatment. The age range of the patients was 4-61 years, and 16 of the 65 were under 13 years of age. Thirty-nine patients suffered from congenital heart disease and 20 from rheumatic heart disease. In 4 no abnormality was discovered, and the remaining 2 were found to be suffering from cardiomyopathies of unknown cause. Catheterization of the right heart was performed in 48 patients, in 9 of whom cine-angiography was also performed. In a further 17 patients, left ventricular catheterization and angiography were carried out either by the Brockenburgh or by retrograde techniques.

Dosage. Adult subjects received $5 \mathrm{mg}$. of DHBP intravenously one hour before the procedure, and in 11 patients this gave satisfactory sedation on its own. In the remaining 54 patients, however, phenoperidine was further required to give an adequate level of sedation; this was given immediately before the intravascular procedure, in a dose of $0.02 \mathrm{mg} . / \mathrm{kg}$. body weight, with a subsequent additional dose if the investigation was prolonged. The total dosage of phenoperidine used varied between 0.02 and $0.04 \mathrm{mg}$. $/ \mathrm{kg}$. body weight. In 8 children between the ages of 4 and 6 years DHBP was given by intrachildren received $4 \mathrm{mg}$. intravenously one hour before. Phenoperidine was again given to a total dose of $0.04 \mathrm{mg} . / \mathrm{kg}$. body weight.

Efficacy. With these drugs, alone or in combination, satisfactory sedation was achieved in 63 of the 65 patients. They remained completely immobile for periods of up to two hours but responded to simple instructions and were fully capable of performing supine leg exercise.

Side-effects. Vomiting occurred in 3 patients and a further 4 experienced nausea while recovering in the ward after the procedure. The respiratory rate fell in all cases receiving phenoperidine, but this never caused anxiety and none of the patients required nalorphine.

In only two instances did the premedication prevent the planned investigation. A man aged 39 years with aortic stenosis complained of general malaise, a feeling of breathlessness, and of the legs "shrinking up into his body", within 10 minutes of the intravenous injection of $5 \mathrm{mg}$. of DHBP. Clinical examination revealed no abnormality, but because of the patient's mental distress the 
TABLE I

DETAILS OF PATIENTS STUDIED

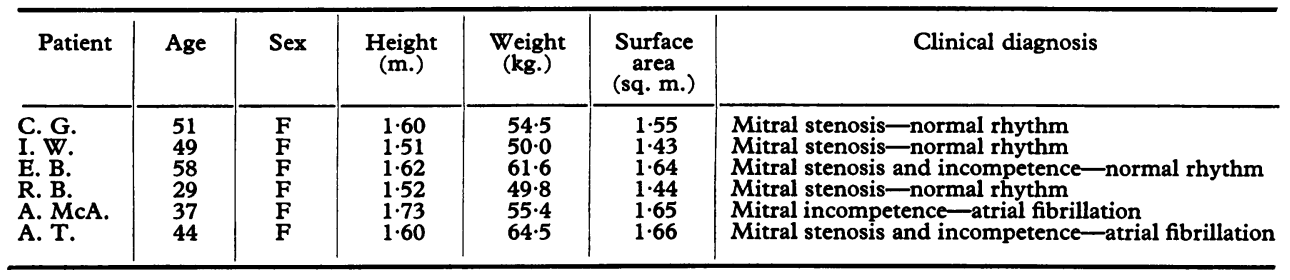

investigation was cancelled. His symptoms persisted for 36 hours. A sense of impending dissolution was experienced by another patient shortly after injection of DHBP but no clinical abnormality was found.

\section{Circulatory Studies}

The pharmacological activity of these drugs on the circulation in man was studied by observing their effects on the pulmonary and systemic circulations in rheumatic heart disease.

\section{METHODS}

Clinical details. Studies were made on 6 patients with mitral valve disease undergoing diagnostic circulatory investigations. The personal and clinical details of these patients are given in Table I.

Plan of investigation. Previous studies have shown that a more stable basal circulatory state may be induced in patients under investigation by a short period of nonfatiguing leg exercise (Taylor et al., 1962). All subjects in the present study were therefore required to carry out light supine leg exercise for five minutes, during which measurements were made to assess the circulatory response to exercise. Thereafter, they were allowed a 15-minute recovery period to permit the return of the circulation to a more basal level. At the end of this period a control study was carried out in which the systemic arterial, pulmonary arterial, and pulmonary wedge pressures were measured for 10 minutes, and during this time the cardiac output was measured at 2-minute intervals. At the end of the control period, 4 patients (C. G., I. W., E. B., and R. B.) were given an intravenous infusion of dehydrobenzperidol (DHBP) in saline in a concentration of $1 \mathrm{mg}$. $/ \mathrm{ml}$. at a rate of $1 \mathrm{ml}$./ min. until a total dose of $10 \mathrm{mg}$. had been administered. Intravascular pressures were recorded continuously for the next hour; the cardiac output was measured at 2-minute intervals for 20 minutes and then at 5-minute intervals to the end of the period of study. Two further patients (A. T. and A. McA.) were given $10 \mathrm{mg}$. DHBP intramuscularly approximately 1 hour before starting the control observations, following which they were given $1.5 \mathrm{mg}$. of phenoperidine as a single acute intravenous injection. Measurements were continued again for a total period of one hour using the technique described.
In all patients systemic and pulmonary arterial blood samples were taken for the determination of oxygen content at the time of the dye dilution curves to allow calculation of the oxygen uptake. Systemic arterial blood samples for the measurement of oxygen and carbon dioxide gas tensions and $p \mathrm{H}$ were taken during the control period and at intervals of $10,30,45$, and 60 minutes after injection of the drug.

Laboratory techniques. Systemic arterial pressure was taken through a nylon catheter, bore $0.8 \mathrm{~mm}$., length $55 \mathrm{~cm}$., introduced percutaneously via the brachial artery and passed into the aortic root; pressures were transduced by a Statham P23Db strain gauge manometer calibrated against previously standardized Reckla aneroid manometers. Pulmonary arterial and wedge pressures were recorded simultaneously by means of a triple lumen cardiac catheter and transduced by Statham P23Db manometers calibrated against an open saline column.

Cardiac outputs were determined by an indicator dilution technique using indocyanine green dye injected via the third lumen of the triple lumen catheter into the pulmonary artery, and sampled in the root of the aorta through the arterial catheter already described. The dye curves were transcribed by a modified Waters $\mathrm{X} 300 \mathrm{~A}$ cuvette densitometer assembly in conjunction with an ultraviolet recorder (N.E.P. Ltd.). By comparison of consecutive cardiac output measurements at the same heart rate, the reproducibility of this dye method has been determined as less than $\pm 0 \cdot 171 . / \mathrm{min}$. at the 95 per cent level of confidence throughout a cardiac output range of $2-101 . / \mathrm{min}$. or \pm 2.72 per cent at a cardiac output of $6.321 . / \mathrm{min}$. This method, together with its validation, an estimate of its errors, and a critical assessment of the theoretical principles upon which it is based, are described in detail elsewhere (Taylor, 1966; Taylor et al., 1967a). During these studies the cardiac output was monitored continuously by means of a Gilford computer, the use and standardization of which will be reported later (Taylor et al., 1967b). The heart rate was determined from a continuously recorded electrocardiogram.

Measurements and calculations. Cardiac output and cardiopulmonary blood volume were calculated according to the conventional Hamilton formula. The dye curve downslope was extrapolated through two whole logarithmic cycles, trapezoidal approximations being made at half second intervals. The minimum number 
of points on the direct plot accepted for trial fitting of the extrapolation was six and in all curves a straight line segment was readily discernible. The calculation of the mean systemic and pulmonary vascular resistances was modified to incorporate a correction for body surface area, the arguments for which have been previously presented (Taylor et al., 1962).

\section{RESULTS}

The primary measurements and derived variables are illustrated in Fig. 1-4. Reference to these figures demonstrates that the circulatory changes produced by these drugs alone or in combination were constantly changing, though distinct trends in the majority of these parameters are clearly discernible.

Circulatory effects of dehydrobenzperidol. The systemic circulatory changes due to the infusion of the drug were consistent in three of the four patients. In three patients (C. G., I. W., and E. B.) the start of the infusion was promptly followed by a fall in systemic vascular resistance which continued throughout the remainder of the 10 minutes the drug was being administered. With completion of the infusion the systemic resistance gradually returned to pre-infusion values with a lag varying between 10 and 30 minutes. In none of these patients was a compensatory increase in heart rate or cardiac output observed, so that the fall in systemic vascular resistance was clearly reflected in the changes in systemic arterial pressure (Fig. 1). In the fourth patient (R. B.), a fall in systemic vascular resistance was not noted until 10 minutes after completion of the infusion of the drug, though there was a small fall in cardiac output during and im- mediately after the infusion. Administration of the drug was associated with no consistent changes in stroke volume in any of the patients.

The changes in the pulmonary circulation due to the drug are illustrated in Fig. 2. The infusion was associated with a small fall in both the pulmonary arterial and pulmonary wedge pressures in all four patients. In two (I. W. and E. B.) completion of the infusion was not accompanied by any further fall, the pulmonary pressures remaining at these lower levels for the remainder of the period of observation. In two other patients (C. G. and R. B.) both pressures continued to fall gradually for up to 30 minutes after stopping the infusion. In all except one patient (I. W.) the reduction in pulmonary vascular pressures was proportionately greater in the pulmonary arterial than in the pulmonary wedge pressures. In these three patients the calculated mean pulmonary vascular resistance was reduced during and after the infusion. In the one exception (I. W.) the fall in the pulmonary arterial and wedge pressures was of a similar order, and this, allied to the small reduction in the cardiac output, resulted in a small increase in the calculated pulmonary vascular resistance. The maximum reductions in the pulmonary vascular pressures were observed in those patients (C. G. and R. B.) with the highest initial pressures. The drug had no consistent effect on the cardiopulmonary blood volume within the one-hour period of the observations.

Circulatory effects of phenoperidine. The changes in the systemic circulation produced by the injection of $1.5 \mathrm{mg}$. phenoperidine were similar in direction but much less in degree than those observed following the infusion of dehydrobenzperidol. Injection
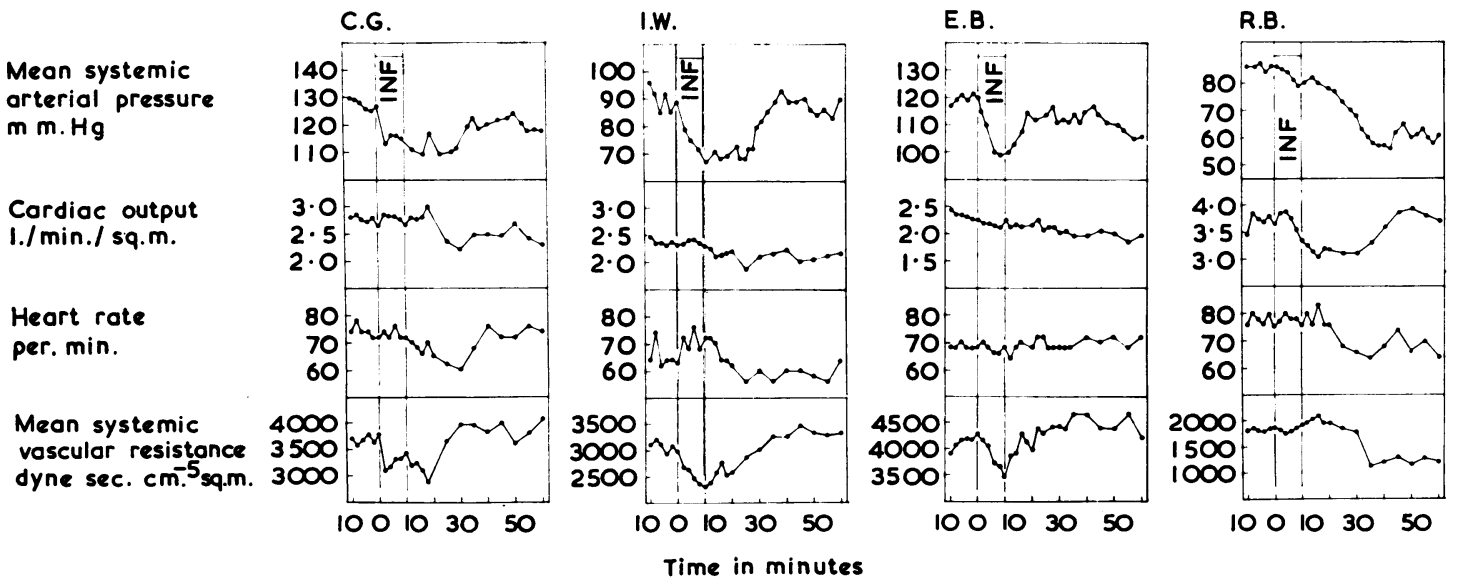

FIG. 1.-The effect of an intravenous infusion of dehydrobenzperidol on the systemic circulation of four patients with mitral valve disease. 


CARDIAC OUTPUT
I./min./ sq.m.
PULMONARY ARTERIAL
AND PULMONARY
WEDGE PRESSURES
mm. Hg
PULMONARY VASCULAR
RESISTANCE
dYNE SEC. ${ }^{-5}$ SQ.m.
CARDIO-PULMONARY
BLOOD VOLUME
ml. sq.m.

CARDIAC OUTPUT

PULMONARY ARTERIAL AND PULMONARY mm. Hg RESISTANC BLOOD VOLC $\mathrm{ml}$. $\mathrm{m}$.
C.G

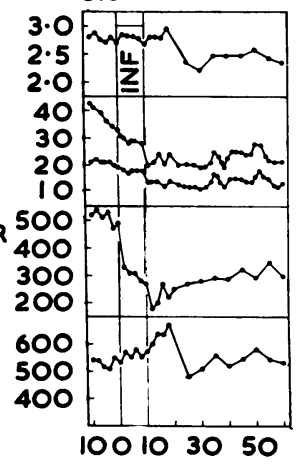

I.W.

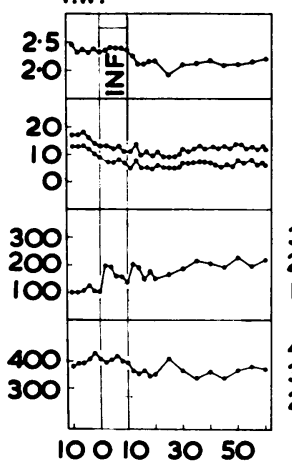

E.8.

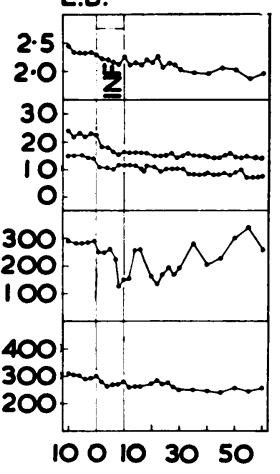

R.B.

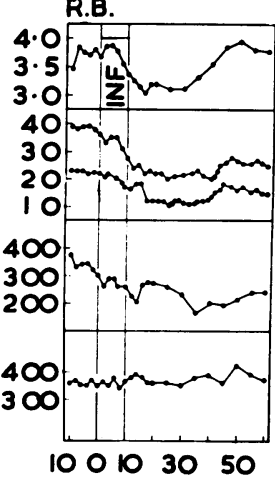

Time in minutes

of the drug was followed by a gradual reduction in the systemic vascular resistance, which, in the absence of appreciable changes in cardiac output, resulted in small reductions in the systemic arterial blood pressure in both patients (Fig. 3). There was no consistent change in heart rate or stroke volume in either patient following the injection. In the pulmonary circulation, the intravenous injection of $1.5 \mathrm{mg}$. phenoperidine produced different responses in the two patients studied (Fig. 4). In one (A. T.) the injection was followed by a consistent and prolonged fall in the pulmonary wedge pressure without change in the pulmonary arterial pressure. The absence of significant change in the cardiac output led to an increase in the calculated pulmonary vascular resistance. In the second patient
(A. McA.) the injection resulted in a transient rise in pulmonary arterial pressure; the pulmonary wedge pressure was only slightly increased. The absence of any material change in cardiac output led to a similar transient increase in the calculated pulmonary vascular resistance. In neither subject did the injection of phenoperidine result in significant changes in the cardiopulmonary blood volume.

Effect of the drugs on total body oxygen uptake. The infusion of dehydrobenzperidol resulted in a reduction in the total body oxygen uptake which continued throughout the infusion in all four patients (Fig. 5). This reduction varied between 20-30 $\mathrm{ml}$./min./sq. m., approximately $20-30$ per cent of the initial resting value. In all 4 patients the decrease

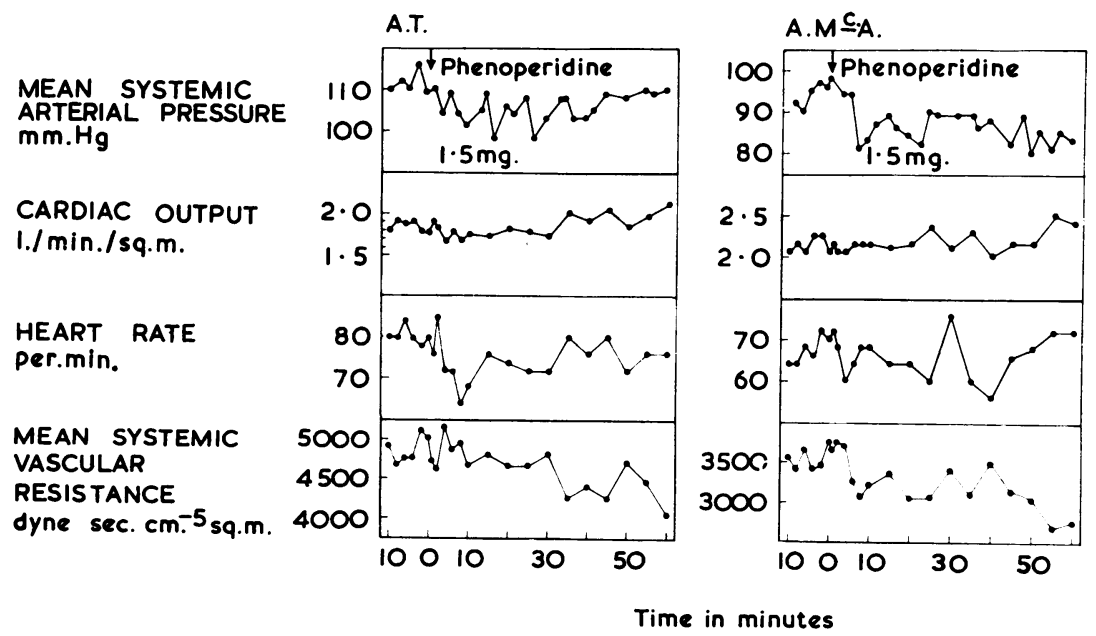

FIG. 3. - The effect of an intravenous injection of phenoperidine on the systemic circulation of two patients with mitral valve disease. 


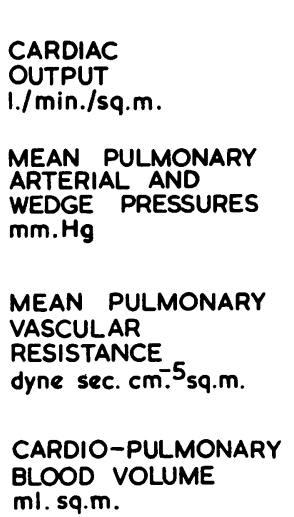

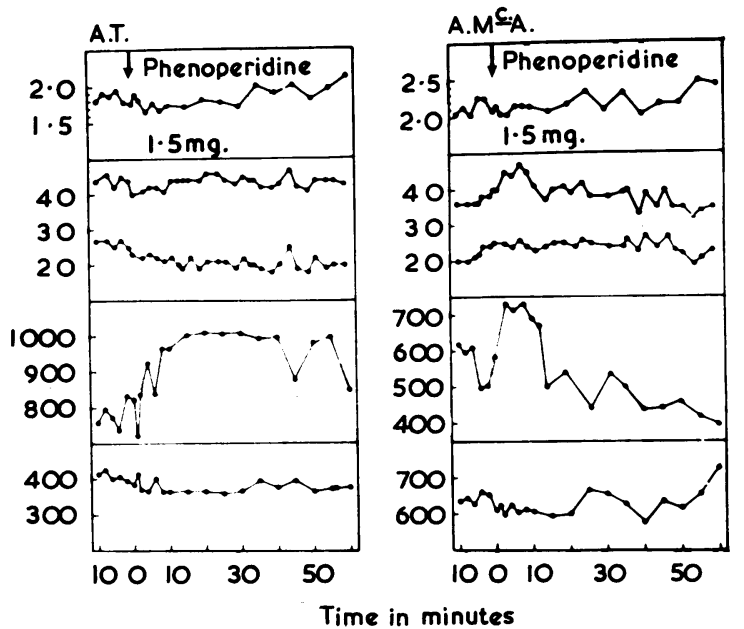

FIG. 4.-The effect of an intravenous injection of phenoperidine on the pulmonary circulation of two patients with mitral valve disease.

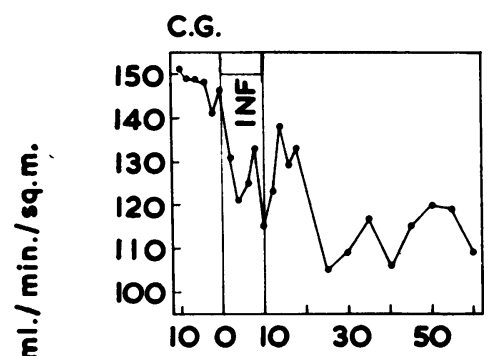

\section{E.B.}

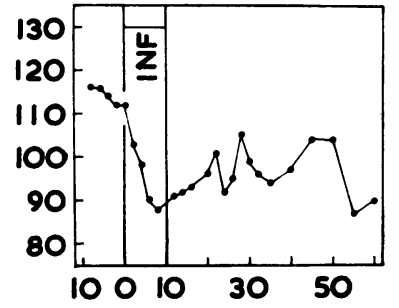

I.W.

R.B.
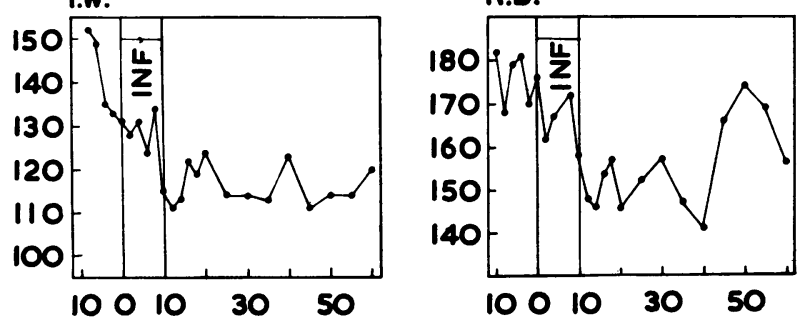

Time in minutes

FIG. 5.-The effect of an infusion of dehydrobenzperidol on the total body oxygen uptake of four patients with mitral valve disease.

in oxygen uptake was maintained for the remainder of the one-hour period of observation. The changes in total body oxygen uptake following the injection of phenoperidine were in a similar direction but much less in degree (Fig. 6).

Effect of drugs on systemic arterial blood gas tensions, $p H$, and percentage oxygen saturation. The infusion of dehydrobenzperidol resulted in no significant change in systemic arterial blood oxygen or carbon dioxide tensions and no change in arterial blood $p \mathrm{H}$ or percentage oxygen saturation in any of the four patients (Fig. 7).

The injection of phenoperidine resulted in significant respiratory depression in both of the patients to whom it was given (Table II). In one 


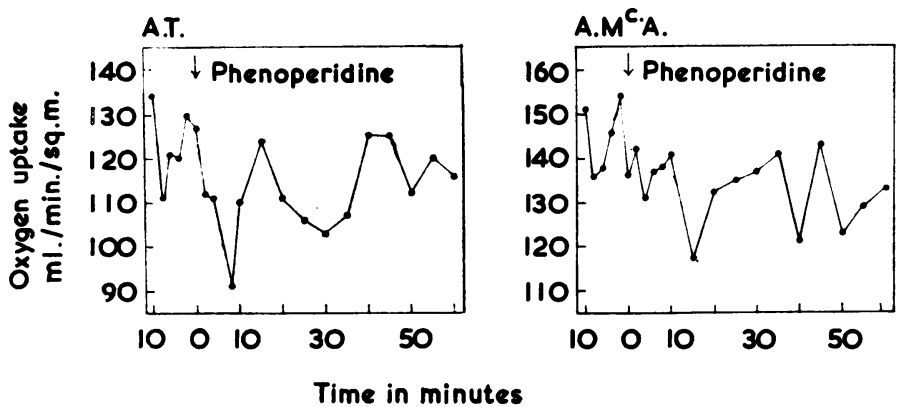

FIG. 6.-The effect of an injection of phenoperidine on the total body oxygen uptake of two patients with mitral valve disease.

patient (A. McA.) the injection of $1.5 \mathrm{mg}$. of the drug was followed by a fall in arterial blood oxygen tension from $102 \mathrm{~mm}$. $\mathrm{Hg}$ to $76 \mathrm{~mm}$. $\mathrm{Hg}$, accompanied by a similar reduction in percentage arterial blood oxygen saturation. The arterial blood carbon dioxide tension was increased from 35 to $48 \mathrm{~mm} . \mathrm{Hg}$ and the $p \mathrm{H}$ reduced from $7 \cdot 40$ to $7 \cdot 34$ over the same period. In the other patient (A. T.) the changes were in a similar direction but were smaller.

\section{Discussion}

An anæsthetic or sedative drug for patients undergoing circulatory investigation needs to allay the natural anxiety of the patient while having minimal effects on the variables being measured. Unfortunately such drugs nearly always have significant effects on the parameters under study. No single drug or group of drugs has yet been shown to fulfil these conflicting demands. An optimum state between the hæmodynamic changes that ac-

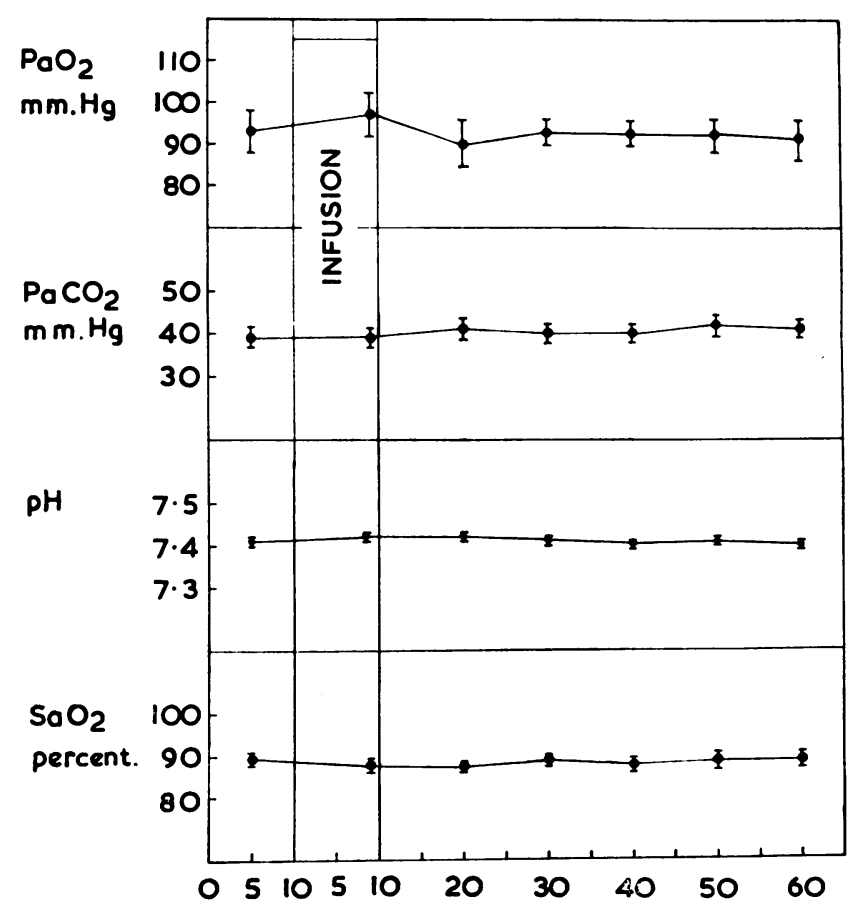

Time in minutes

FIG. 7.-The effects of an intravenous infusion of dehydrobenzperidol on the systemic arterial blood gases, $p \mathrm{H}$, and oxygen saturation. 
TABLE II

BLOOD GAS CHANGES FOLLOWING PHENOPERIDINE INJECTION

\begin{tabular}{|c|c|c|c|c|c|c|c|c|}
\hline \multirow[t]{2}{*}{ Time } & \multicolumn{2}{|c|}{$\mathrm{Po}_{2}$} & \multicolumn{2}{|c|}{$\mathrm{PCO}_{2}$} & \multicolumn{2}{|c|}{$p \mathrm{H}$} & \multicolumn{2}{|c|}{$\mathrm{O}_{2}$ saturation } \\
\hline & A. McA. & A. T. & A. McA. & A. T. & A. McA. & A. $T$. & A. McA. & A. $T$. \\
\hline $\begin{array}{c}\text { Pre-injection } \\
10 \text { minutes } \\
30 \text { minutes } \\
45 \text { minutes } \\
60 \text { minutes }\end{array}$ & $\begin{array}{r}102 \\
76 \\
76 \\
74 \\
83\end{array}$ & $\begin{array}{l}82 \\
72 \\
76 \\
73 \\
82\end{array}$ & $\begin{array}{l}35 \\
48 \\
48 \\
52 \\
48\end{array}$ & $\begin{array}{l}40 \\
44 \\
44 \\
44 \\
42\end{array}$ & $\begin{array}{l}7.40 \\
7.35 \\
7.34 \\
7.34 \\
7 \cdot 36\end{array}$ & $\begin{array}{l}7 \cdot 42 \\
7.37 \\
7.38 \\
7.38 \\
7 \cdot 39\end{array}$ & $\begin{array}{l}94 \cdot 2 \\
89 \cdot 3 \\
89.5 \\
87.2 \\
92 \cdot 5\end{array}$ & $\begin{array}{l}92.9 \\
89.7 \\
91.4 \\
91.5 \\
90 \cdot 2\end{array}$ \\
\hline
\end{tabular}

company emotion and those that accompany druginduced sleep must be sought. All the inhalation agents and the majority of sedative drugs used in the past have failed to fulfil these important criteria. The early promise of the so-called "tranquillizer" drugs such as the phenothiazines etc. in this respect was unfortunately shortlived owing largely to their inadequate sedative effects in children under investigation. However, the advent of the neuroleptanalgesic agents brought new hopes, owing to their unique pharmacological properties. The cumbersome term "neuroleptanalgesia" was apparently coined by de Castro and Mundeleer (1959) to describe " a form of anæsthesia brought about by a combination of a neuroleptic and an analgesic without the use of barbiturates or volatile inhalation anæsthetics". Both dehydrobenzperidol and phenoperidine appear to combine these effects, allaying anxiety and producing an indifference to painful stimuli. However, while the administration of dehydrobenzperidol gave rise to no clinical sideeffects and few respiratory changes, the powerful emetic action of phenoperidine and the marked respiratory depression that follows its use demand the help of a skilled anæsthetist. In fact, phenoperidine seems to have less advantage than the barbiturates though it is a far more powerful analgesic drug.

Both drugs produced conspicuous changes in both the systemic and pulmonary circulations, but these were most obvious after dehydrobenzperidol. The immediate fall in blood pressure due to the reduction in systemic resistance that promptly followed the infusion of the drug was unaccompanied by any compensatory increase in heart rate or cardiac output. In fact, in three patients, both the heart rate and cardiac output declined somewhat after the drug. These findings taken together have three implications. First, the fact that the heart rate and cardiac output were not raised during the control period and did not promptly fall after the drug would imply that these patients were in a relatively basal state at the time of its administration. Secondly, the abrupt reduction in systemic and pulmonary vascular resistances that followed its infusion implies an immediate and direct effect on the resistance vessels in both circuits. Thirdly, the absence of any compensatory reflex elevation of the heart rate and cardiac output to counteract the fall in systemic blood pressure suggests a druginduced insensitivity of the afferent baroreceptor mechanisms or blockade of the normal catecholamine-sympathetic efferent reflex arc. As the drug appears to antagonize both adrenaline and noradrenalin in the experimental animal, the latter mechanism is the more likely. Perhaps the most significant effect of dehydrobenzperidol in the present connexion is in lowering the pulmonary vascular pressures, particularly those that are raised. In fact, in the two patients with initially high pulmonary, arterial, and wedge pressures, the drug rapidly reduced each to normal levels; the changes in pulmonary vascular resistance were of a similar order. Thus in spite of its other advantages, the use of dehydrobenzperidol as a neuroleptanalgesic agent may cause errors in assessment.

Although these results demonstrate that perhaps the most notable circulatory activities of dehydrobenzperidol are peripheral, the effect of these drugs on the cerebral mechanisms of circulatory control has to be considered. Reports directly concerning such mechanisms in man are almost negligible compared with the great numbers relating to regulations of peripheral circulation. However, the increasing numbers of animal studies have dispelled any doubt that visceral changes, particularly cardiovascular ones, can be evoked from the cerebral cortex and its immediate underlying connexions. Although the exact functional significance of many of the reactions reported is obscure, in general it appears that frontal lobe stimulation results in cardio-accelerator and systemic pressor responses (Hoff and Green, 1936). It is, therefore, not surprising that drugs such as the neuroleptanalgesics used in the present study should result in a fall in systemic vascular resistance, blood pressure, heart rate, and cardiac output at the same time as producing their psychodepressor effects. 


\section{SUMMARY}

The neuroleptanalgesic drugs dehydrobenzperidol and phenoperidine have been used alone and in combination in 65 patients undergoing routine diagnostic cardiovascular investigations. In 6 patients detailed observations were made to assess the circulatory effects of these drugs.

Satisfactory sedation was obtained with dehydrobenzperidol alone in 11 of the 65 patients. In the remainder phenoperidine was necessary in addition to obtain adequate sedation. Two of the patients developed abnormal psychomotor behaviour after dehydrobenzperidol. Significant respiratory depression was noted after phenoperidine but not after dehydrobenzperidol.

Dehydrobenzperidol resulted in widespread vasodilatation of the systemic and pulmonary circulatory beds, probably due to a direct effect on the resistance vessels. The resulting fall in systemic blood pressure did not result in a reflex increase in heart rate and cardiac output possibly owing to catecholamine antagonism. The drug rapidly reduced the pulmonary pressures to normal when they had previously been raised; this activity of the drug may give rise to erroneous hæmodynamic results. By the same token, this effect on the pulmonary pressures may have important therapeutic implications in its use in patients with congestive heart failure.

Phenoperidine had similar but less hæmodynamic activities.

While dehydrobenzperidol may have uses as a tranquillizing agent during diagnostic cardiovascular investigations, it may invalidate hæmodynamic conclusions, particularly as to the pulmonary circulation. Phenoperidine appears to offer no advantages over other more commonly used agents, and in addition has the specific hazard of being a powerful respiratory depressant.
The authors wish to acknowledge their gratitude to Professor K. W. Donald for the use of the facilities of his department and for his encouragement throughout, and to Dr. R. M. Marquis for allowing us to study his patients. The authors would also like to thank Sister Mitchell, Mr. Ramsay, and the technical staff of the Department of Medicine for their invaluable help at all stages of this work.

\section{REFERENCES}

Brown, A. S. (1963). Neuroleptanalgæsia: The present position for neurosurgery. Irish $\mathcal{F}$. med. Sci., p. 535.

(1964). Neuroleptanalgesia for surgical treatment of Parkinsonism. Ancesthesia, 19, 70.

- Horton, J. M., and MacRae, W. R. (1963). Anæsthesia for neurosurgery. Anasthesia, 18, 143.

de Castro, G., and Mundeleer, P. (1959). Anesthésie sans sommeil "Neuroleptanalgésie" (Film). Acta chir.belg., $58,689$.

Hoff, E. C., and Green, H. D. (1936). Cardiovascular reactions induced by electrical stimulation of the cerebral cortex. Amer. F. Physiol., 117, 411.

Janssen, P. A. J., Niemegeers, C. J. E., Schellekens, K. H. L., Verbruggen, F. J., and Van Nueten, J. M. (1963). The pharmacology of Dehydrobenzperidol, a new potent and short acting neuroleptic agent chemically related to Haloperidol. Arzneimittel-Forsch., 13, 205.

Rollason, W. N., and Sutherland, J. S. (1963). Phenoperidine (R1406) a new analgesic. Ancesthesia, 18, 16.

Taylor, S. H. (1966). Measurements of the cardiac output in man. Measurements in medicine. Proc. roy. Soc. Med., 59, Suppl., p. 35.

—, Kennelly, B. M., Mackenzie, G. J., Sutherland, G. R., Hutchison, D. C. S., Staunton, H. P., and Donald, K. W. (1967a). A comparison of the direct Fick and dye dilution methods of measurements of the cardiac output in man. In preparation.

—, Macdonald, H. R., Robinson, M. C., and Sapru, R. P. (1967b). Computers in cardiovascular investigation. Brit. Heart $\mathcal{F}$. In the press.

-, Sutherland, G. R., Hutchison, D. C. S., Kidd, B. S. L., Robertson, P. C., Kennelly, B. M., and Donald, K. W. (1962). The effects of intravenous guanethidine on the systemic and pulmonary circulations in man. Amer. Heart F., 63, 239. 